\title{
Distribution of Geochemical Fractions of Phosphorus in Surface Sediment in Daya Bay, China
}

\author{
Hongping Liao ${ }^{1,2}$, Ciguang Pan ${ }^{1,2}$, Lian Gan ${ }^{1,2}$, Zhixin Ke ${ }^{3}$ (I) and Huijuan Tang 1,2,* \\ 1 Joint Laboratory of Guangdong Province and Hong Kong Region on Marine Bio-Resource Conservation and \\ Exploitation, South China Agricultural University, Guangzhou 510642, China; \\ 20186140006@stu.scau.edu.cn (H.L.); 20192067003@stu.scau.edu.cn (C.P.); ganlian@scau.edu.cn (L.G.) \\ 2 College of Marine Sciences, South China Agricultural University, Guangzhou 510642, China \\ 3 Key Laboratory of Tropical Marine Bio-resources and Ecology, South China Sea Institute of Oceanology, \\ Chinese Academy of Sciences, Guangzhou 510301, China; kzx@scsio.ac.cn \\ * Correspondence: tanghj@scau.edu.cn; +86-13570508738
}

Received: 14 May 2020; Accepted: 16 June 2020; Published: 19 June 2020

\begin{abstract}
Surface sediment samples were collected from 19 sites throughout Daya Bay, China, to study the concentrations, and spatial distributions of different fractions of phosphorus through sequential extraction methods. Like many coastal and marine areas, De-P was the dominant form of $\mathrm{P}$, contributing $47.5 \%$ of TP, followed by O-P, contributing $25.5 \%$ of TP. Ex-P and Fe-P contribute the lowest to TP. The concentration of sedimentary TP ranged from $290.3 \sim 525.1 \mu \mathrm{g} / \mathrm{g}$, with the average of $395.3 \mu \mathrm{g} / \mathrm{g}$, which was a similar range to other estuaries and coastal areas. Based on the spatial distribution, Pearson correlation and Principal component analysis, different fractions of phosphorus showed different spatial distributions due to different sources. The molar ratio of organic carbon to phosphorus (TOC/O-P) ranged from 199 to 609, with the average of 413, which was much higher than the Redfield ratio, suggesting terrestrial sources of organic matter in Daya Bay surface sediment. The average bioavailable phosphorus was $149.6 \mu \mathrm{g} / \mathrm{g}$ and contributed $37.8 \%(24.6 \sim 56.0 \%)$ of TP, indicating that the surface sediments of Day Bay act as an important internal source of $\mathrm{P}$.
\end{abstract}

Keywords: fractions of phosphorus; surface sediment; distribution; Daya Bay

\section{Introduction}

Phosphorus $(\mathrm{P})$ is one of the most significant macronutrients in aquatic ecosystem. It plays an important role in phytoplankton growth, controls the primary production, and further influences aquatic biological structures and functions [1,2]. Naturally, the aquatic ecosystems are inclined to be $P$ limited, due to their relatively low content and high requirement [3].

Estuaries and coastal bays are regions of land-ocean interactions. Increased inputs of nutrient from continental sources due to dense human population and intense land use have resulted in degradation of the coastal ecosystems [4]. When entering the coastal environment, only minimal $\mathrm{P}$ is biologically recycled within the water column, and most is finally settled and combined with sediment due to physical, geochemical and biological processes. However, incorporated sediment $\mathrm{P}$ can be released under appropriate $\mathrm{pH}$, and redox potential conditions, etc [5]. Therefore, sediment acts as an important sink or source for P cycling [6]. When external inputs are controlled, P released from the sediments will still adversely affects the water quality in the long term [7]. The mobility of sediment $P$ mainly depends on the composition of different fractions of $\mathrm{P}$ [8]. Research on the composition and distribution of $\mathrm{P}$ fractions in sediment is important for the determination of the risk of $\mathrm{P}$ release and to anticipate the potential effects on aquatic ecosystems. 
Daya Bay is situated in one of the most rapidly developing areas in southern China. Industries including two nuclear power stations, stevedoring and petrochemical industries, printing and plastic factories have arisen around the coastal area in recent decades [9]. Furthermore, from 1987 to 2010 , marine cage aquaculture had expanded from 142.5 to 1600 t [10]. Simultaneously, tourism and urbanization also rapidly developed [11]. As a result of these strong heavy anthropogenic activities, Daya Bay has frequently experienced severe eutrophication and harmful algal blooms (HAB) [12]. Moreover, increased human activity has altered the balance of nutrients $[4,13]$. Based on the long-term ratio of dissolved inorganic nitrogen (DIN) to phosphate, phytoplankton in Daya Bay shifted from nitrogen-limited to phosphate-limited since the mid-1990s [4], which has been attributed to increased external nitrogen loading and decreased external P loading. However, research on benthic fluxes of nutrient found positive diffusion of DIN and phosphate from sediment to overlying water, indicating sediment as an important source of this nutrient [7]. Daya Bay was one of the most intensively researched coastal areas in China, the sediment contamination also received considerable attention. However, most of the sediment researches are mainly focused on heavy metals $[8,14,15]$ and persistent organic pollutants [16,17]. Compared with research on the above pollutants and research on other coastal areas [2,18], information on geochemical $\mathrm{P}$ fraction in the sediments of Daya Bay is rather limited, especially when the ecosystem was considered to be P-limited $[4,13]$. Studies on sediment $P$ in Daya Bay are important to know the balance and the circulation of $\mathrm{P}$ in the ecosystem.

In this study, the content of different fractions of $\mathrm{P}$, their spatial distribution, factors influencing their distributions, and the content of total nitrogen and total organic carbon were analyzed for further understanding of the current P levels and sources of sediment P in Daya Bay ecosystems.

\section{Materials and Methods}

\subsection{Study Sites}

Located in the northern part of the South China Sea, the semi-enclosed Daya Bay has an area approximately $600 \mathrm{~km}^{2}$ (Figure 1). It is about $15 \mathrm{~km}$ from west to east and $30 \mathrm{~km}$ from north to south. Aotou and Yaling Bay, Fanhe Harbor, and Dapeng Cove are the main sub-basins in Daya Bay. The Aotou and Yaling sub-basins are in the northwest of Daya Bay, and functions as a busy port and cage aquaculture basis. Located in the northeast, Fanhe Harbor is a base of shellfish aquaculture and pond aquaculture around the bay, and Dapeng Cove, in the southwest, also has cage aquaculture and pond aquaculture nearby the coast. There is no major river discharge into the bay, except for the small Danao River in the northwest, so the water mainly originates from the South China Sea.

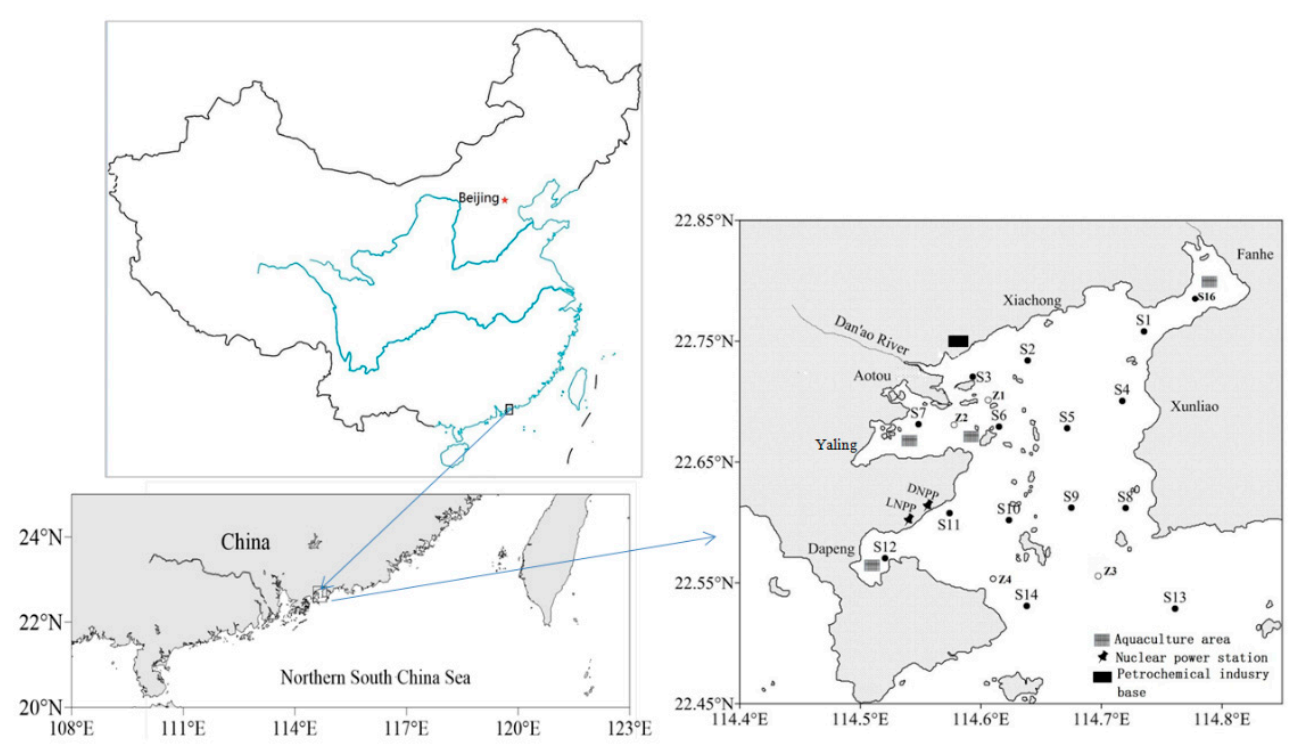

Figure 1. Daya Bay location and sampling sites (Labeled as S1-S14, S16, and Z1-Z4). 


\subsection{Sampling and Analysis}

To represent the whole bay including the three sub-basins, north, west, central and outer bay, surface sediments of 19 sampling sites (Figure 1) were collected through a stainless sediment sampler in spring 2017. At the same time, depth, bottom temperature (Temp), asalinity and redox potential (Eh) were measured in situ through a YSI 6600 multi-probe sensor (Yellow Springs Instrument Co., Yellow Springs, OH, USA). Undisturbed surface sediments (top $5 \mathrm{~cm}$ layer) were placed in polypropylene bags and preserved at $-20{ }^{\circ} \mathrm{C}$. Then, the frozen sediments were freeze-dried, homogenized, grounded and sieved with a nylon 60-mesh ( $245 \mu \mathrm{m}$ in diameter). The sieved samples were then kept in polypropylene bags until further analysis. Total nitrogen (TN) and total organic carbon (TOC) were measured through an elemental analyzer (FlashEA, 1112HT, Thermo Electron, Italy). Prior to analysis of TOC, inorganic carbon in each subsample was removed with $1 \mathrm{M} \mathrm{HCl}$ for $3 \mathrm{~h}$ [19].

\subsection{Extraction Method for Phosphorus}

Sequential extraction procedures (SEDEX) [20] were used to determine different fractions of $P$. According to this method, five sedimentary $P$ reservoirs are defined: exchangeable $P(E x-P)$, iron-bound $\mathrm{P}(\mathrm{Fe}-\mathrm{P})$, authigenic $\mathrm{P}(\mathrm{Ca}-\mathrm{P})$, detrital apatite $\mathrm{P}(\mathrm{De}-\mathrm{P})$ and organic $\mathrm{P}(\mathrm{O}-\mathrm{P})$. Inorganic $\mathrm{P}(\mathrm{I}-\mathrm{P})$ in sediments was calculated as the sum of four forms excluding O-P. Total P (TP) was the sum of all the five forms. For each subsample, about $0.5 \mathrm{~g}$ sieved sediments was conducted according to the step-wise procedures of Ruttenberg [20] and Bastami et al. [21] (Table 1). After each step, the extraction was centrifuged, and the supernatant analyzed for phosphates through spectrophotometric phosphomolybdate blue method.

Table 1. Phosphorus fraction procedures.

\begin{tabular}{|c|c|c|}
\hline Extraction Agent & Extraction Condition $\left(25^{\circ} \mathrm{C}\right)$ & P-Fraction \\
\hline Step 1: $1 \mathrm{M} \mathrm{MgCl}_{2}(\mathrm{pH}=8.0)$. & $\begin{array}{l}\text { Shaking for } 2 \mathrm{~h} \text { twice, wash with pure water for } \\
2 \mathrm{~h}\end{array}$ & $\mathrm{E} x-\mathrm{P}$ \\
\hline $\begin{array}{l}\text { Step 2: } 0.30 \mathrm{M} \mathrm{Na} \text {-citrate } 1.0 \mathrm{M} \mathrm{NaHCO}_{3} \\
\text { ( } \mathrm{pH} 7.6 \text { ), } 1.125 \mathrm{~g} \text { of Na-dithionite in } 45 \mathrm{~mL} \\
\text { of citrate bicarbonate solution }\end{array}$ & $\begin{array}{l}\text { Shaking for } 8 \mathrm{~h} \text {; wash with } \mathrm{MgCl}_{2} \text { and pure } \\
\text { water for } 2 \mathrm{~h} \text { respectively }\end{array}$ & Fe-P \\
\hline $\begin{array}{l}\text { Step 3: } 1 \mathrm{M} \text { Na-acetate buffered to } \mathrm{pH} 4 \\
\text { with acetic acid }\end{array}$ & $\begin{array}{l}\text { Shaking for } 6 \mathrm{~h} \text {, wash with } \mathrm{MgCl}_{2} \text { and pure } \\
\text { water for } 2 \mathrm{~h} \text {, respectively }\end{array}$ & Ca-P \\
\hline Step 4: $1 \mathrm{M} \mathrm{HCl}$ & Shaking for $16 \mathrm{~h}$ & De-P \\
\hline Step 5: Ash at $550{ }^{\circ} \mathrm{C} 1 \mathrm{M} \mathrm{HCl}$ & $\begin{array}{l}1 \mathrm{M} \mathrm{HCl} \mathrm{extraction} \mathrm{for} 16 \mathrm{~h} \text { of residue ashed at } \\
550^{\circ} \mathrm{C} \text { for } 2 \mathrm{~h}\end{array}$ & $\mathrm{O}-\mathrm{P}$ \\
\hline
\end{tabular}

\subsection{Statistical Analysis}

Statistical analysis was conducted with IBM SPSS Statistics 22.0 (IBM, Armonk, NY, USA). The normality of the data was tested using the Shapiro-Wilk Test. When the data were normally distributed $(p<0.05)$, Pearson correlation (PC) analysis was performed to determine correlations between the different forms of phosphorus, TN, TOC, Temp, Eh and Salinity. Principle component analysis (PCA) was also applied to determine the relationships among different forms of phosphorus.

\section{Results}

\subsection{Physiochemical Properties of Surfaces Sediments}

The depth of different sites of Daya Bay ranged between 3.3 and $20.0 \mathrm{~m}$, with an average of $10 \mathrm{~m}$. Sediment temperature during the sampling period ranged between 20.4 to $24.9^{\circ} \mathrm{C}$. Bottom salinity and Eh ranged from 31.0 to 34.4 and -61.0 to $-356.0 \mathrm{mv}$, respectively. TN and TOC contents ranged from 0.94 to 2.55 and 4.86 to $22.76 \mathrm{mg} / \mathrm{g}$, respectively (Table 2). The spatial distribution of TN and TOC 
contents were highly coincident, with the highest contents at site S4 and S12, and the lowest at sites S11, S8 and S9 (Figure 2).

Table 2. Physiochemical properties of surfaces sediments of Daya Bay.

\begin{tabular}{ccccccc}
\hline Items & Depth $(\mathbf{m})$ & Salinity & Temp $\left({ }^{\circ} \mathbf{C}\right)$ & Eh $(\mathbf{m v})$ & TN $(\mathbf{m g} / \mathbf{g})$ & TOC (mg/g) \\
\hline Mean & 10.9 & 32.6 & 22.2 & -175.2 & 1.84 & 15.54 \\
Max & 20.0 & 34.4 & 24.9 & -61.0 & 2.55 & 22.76 \\
Min & 3.3 & 31.0 & 20.4 & -356.0 & 0.94 & 4.86 \\
\hline
\end{tabular}

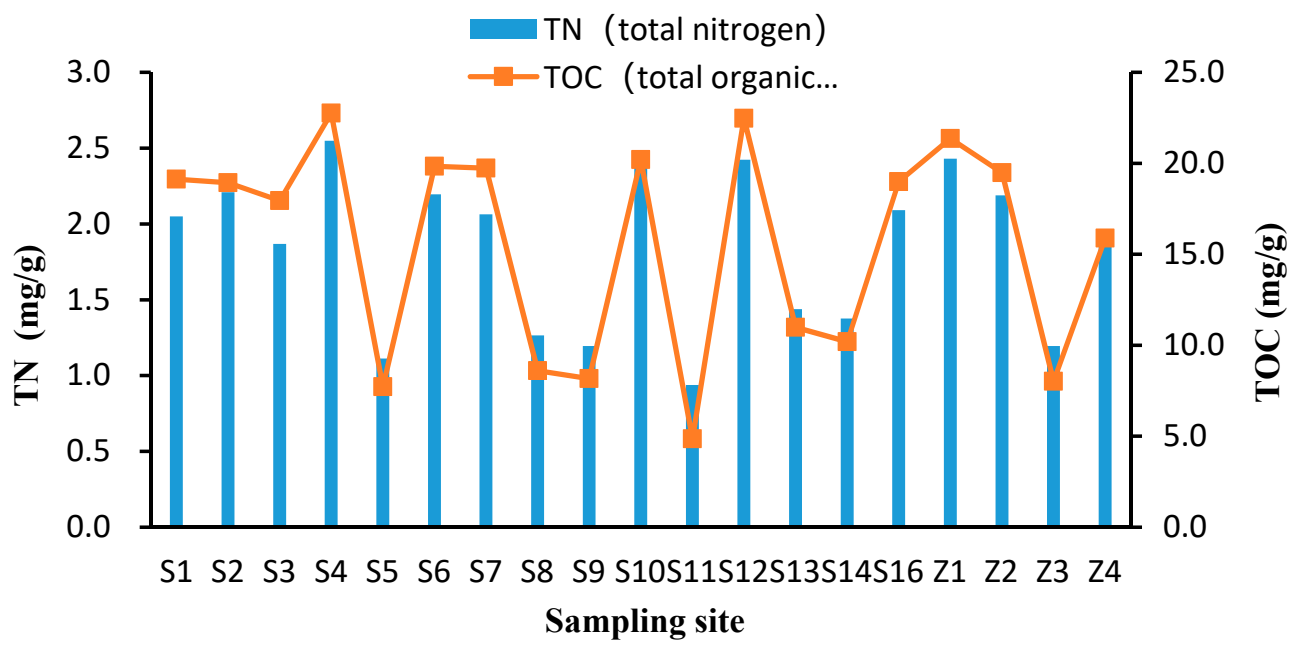

Figure 2. Dynamics of total nitrogen (TN) and total organic carbon (TOC) in the surface sediments of Daya Bay, China.

\subsection{Spatial Distribution of P Species in Surface Sediments}

In surface sediment of Daya Bay, the concentrations of different P species and TP present quite different spatial distributions (Figure 3). Ex-P content ranged from 4.49 to $45.4 \mu \mathrm{g} / \mathrm{g}$, with an average concentration of $15.67 \mu \mathrm{g} / \mathrm{g}$. The relative contribution of Ex-P to TP ranged from 1.01 to $15.6 \%$ (Figure 4), with the highest content at the mouth of Aotou Bay, followed by the central island site. The concentration of Fe-P ranged from 8.4 to $172.0 \mu \mathrm{g} / \mathrm{g}$, with an average of $33.2 \mu \mathrm{g} / \mathrm{g}$. Its relative contribution ranged from $2.9 \sim 35.7 \%$, with the highest content and contribution at the outer bay site, followed by the central bay site. Ca-P content ranged from $15.2 \sim 274.3 \mu \mathrm{g} / \mathrm{g}$, with an average concentration of $57.9 \mu \mathrm{g} / \mathrm{g}$. Its relative contribution ranged from $3.3 \sim 62.0 \%$, with the highest content and contribution in the northwest, where the Danao River flows in. Ca-P in most other areas was quite evenly distributed. De-P content ranged from 59.0 to $318.2 \mu \mathrm{g} / \mathrm{g}$, with an average concentration of $187.8 \mu \mathrm{g} / \mathrm{g}$. Its relative contribution ranged from $13.3 \sim 61.5 \%$; the highest content and contribution occurred at the mouth of Dapeng cove, and the lowest value occurred at the northwest site where the Danao River flows in. O-P content ranged from49.3 156.5 $\mu \mathrm{g} / \mathrm{g}$, with the average concentration of $100.7 \mu \mathrm{g} / \mathrm{g}$. Its relative contribution ranged from $10.2 \sim 48.2 \%$, with the highest content and contribution north-east of the bay. I-P content, which includes the sum of the former four species of $\mathrm{P}$, contributes $51.0 \sim 89.8 \%$ of the TP. TP content ranged from $290.3 \sim 525.1 \mu \mathrm{g} / \mathrm{g}$ with the average concentration of $395.3 \mu \mathrm{g} / \mathrm{g}$. TP content was relatively higher in Yaling Bay, Dapeng Cove, north coastal area, and the outer bay site. On average, the percentage of different $\mathrm{P}$ forms relative to TP were De-P $(47.5 \%)>\mathrm{O}-\mathrm{P}$ $(25.5 \%)>$ Ca-P $(14.7 \%)>$ Fe-P $(8.4 \%)>$ Ex-P $(4.0 \%)$. 

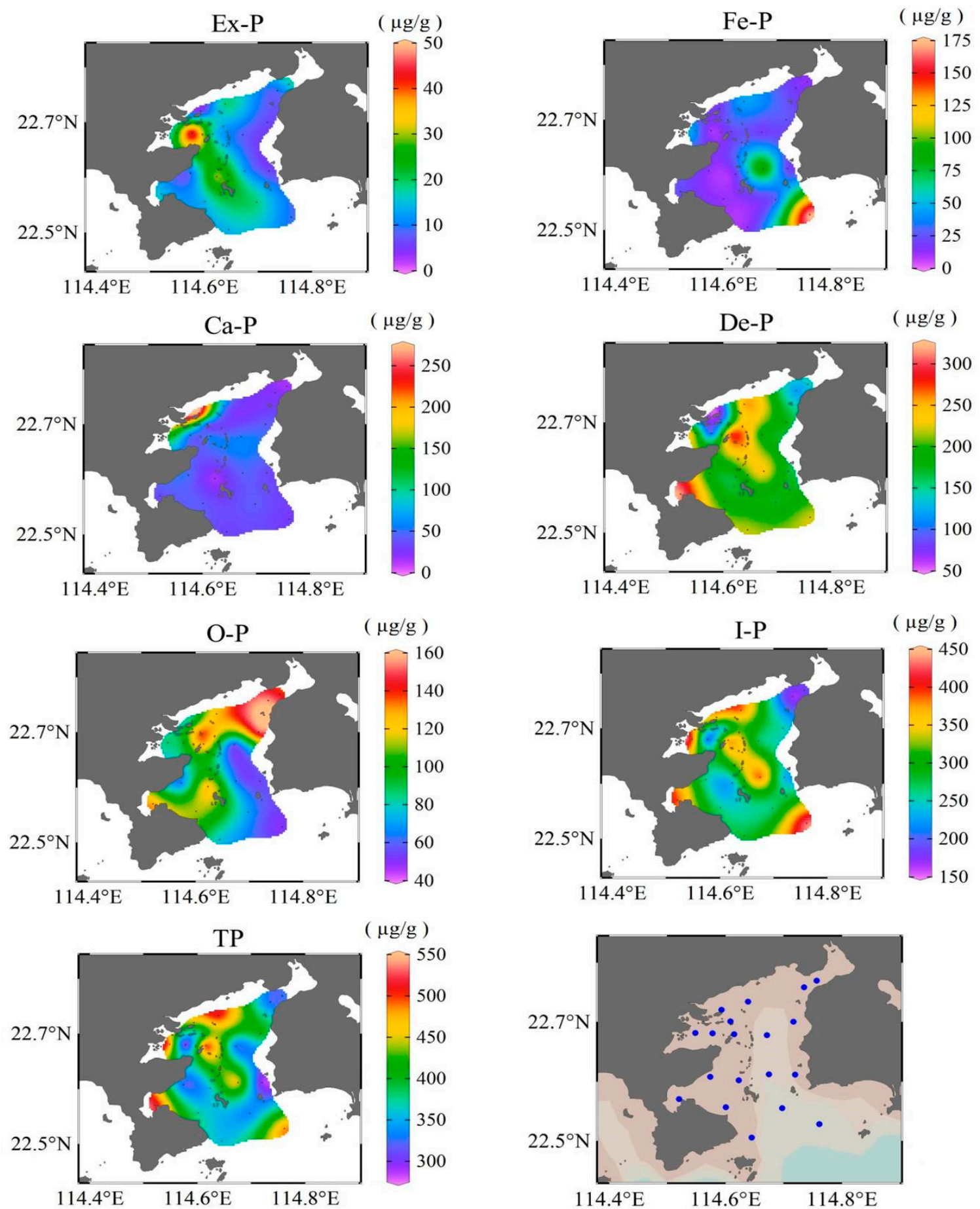

Figure 3. Spatial distributions of different $\mathrm{P}$ fractions in the sediment of Daya Bay, China. 


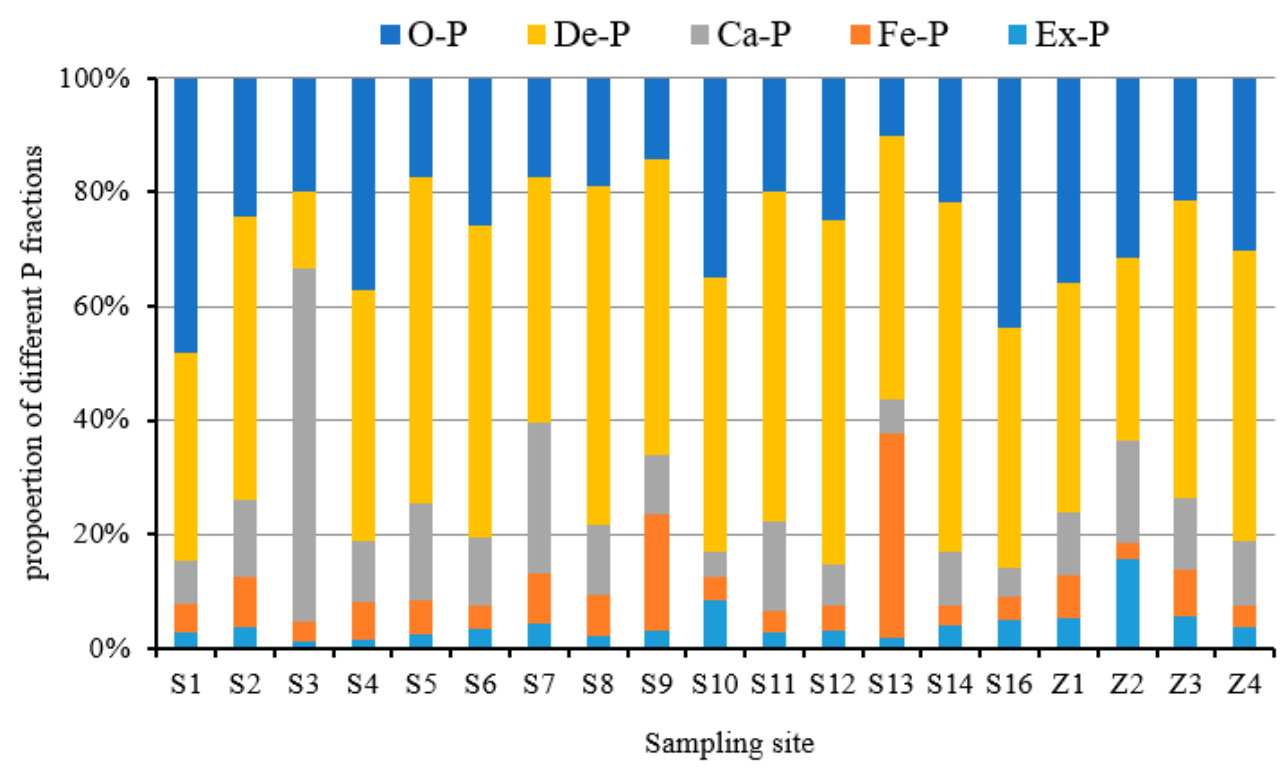

Figure 4. Composition of different $\mathrm{P}$ fractions in the surface sediment of Daya Bay, China.

\subsection{Correlation and Principal Component Analysis}

Pearson correlations among different $\mathrm{P}$ species, TP, TN and TOC, were analyzed (Table 3). Ex-P did not significantly correlate with any other indicators $(p>0.05)$. Both Fe-P and De-P were significantly correlated with I-P and TP $(p<0.05)$, and O-P, TN and TOC showed a positive and significant correlation with each other $(p<0.01)$. Principle component analysis is widely used to verify and quantify pollution sources. Based on PCA, three components (PC1, PC2 and PC3) accounting for $82.5 \%$ of the total variance were extracted (Figure 5). PC1 had high positive loadings on variables TN, TOC and O-P, accounting for $34.7 \%$ of the total variance. PC2 had high loadings for variables TP, I-P, De-P, and Fe-P, accounting for $31.8 \%$ of the total variance. PC3 showed high loading for Ca-P, accounting for $16.0 \%$ of the total variance. 
Table 3. Pearson correlation (PC) coefficient matrix of different $\mathrm{P}$ fractions, total nitrogen (TN), and total organic content (TOC) in the surface sediments of Daya Bay.

\begin{tabular}{|c|c|c|c|c|c|c|c|c|c|c|c|c|}
\hline & Ex-P & Fe-P & Ca-P & De-P & IP & O-P & TP & TN & TOC & Salinity & Temp & Eh \\
\hline Ex-P & 1 & & & & & & & & & & & \\
\hline Fe-P & -0.176 & 1 & & & & & & & & & & \\
\hline Ca-P & -0.189 & -0.09 & 1 & & & & & & & & & \\
\hline De-P & -0.094 & 0.306 & -0.358 & 1 & & & & & & & & \\
\hline IP & -0.169 & $0.614^{* *}$ & 0.369 & $0.632^{* *}$ & 1 & & & & & & & \\
\hline $\mathrm{O}-\mathrm{P}$ & 0.144 & -0.394 & -0.158 & -0.029 & -0.3 & 1 & & & & & & \\
\hline $\mathrm{TP}$ & -0.112 & 0.463 * & 0.313 & $0.643^{* *}$ & $0.906^{* *}$ & 0.132 & 1 & & & & & \\
\hline $\mathrm{TN}$ & 0.385 & -0.235 & 0.024 & -0.008 & -0.054 & $0.856^{* *}$ & 0.324 & 1 & & & & \\
\hline TOC & 0.349 & -0.238 & 0.122 & -0.047 & -0.021 & $0.844^{* *}$ & 0.353 & $0.989 * *$ & 1 & & & \\
\hline Salinity & -0.014 & 0.422 & -0.328 & 0.220 & 0.131 & $-0.705^{* *}$ & -0.177 & $-0.650 * *$ & $-0.708^{* *}$ & 1 & & \\
\hline Temp & -0.161 & -0.016 & $0.533^{*}$ & -0.338 & 0.094 & 0.409 & 0.280 & 0.394 & $0.471^{*}$ & $-0.632 * *$ & 1 & \\
\hline Eh & -0.376 & -0.042 & -0.330 & 0.117 & -0.207 & -0.266 & -0.333 & $-0.551 *$ & $-0.574 *$ & 0.359 & -0.230 & 1 \\
\hline
\end{tabular}

${ }^{*}$ Significant correlation at $p<0.05$. ** Significant correlation at $p<0.01$ 


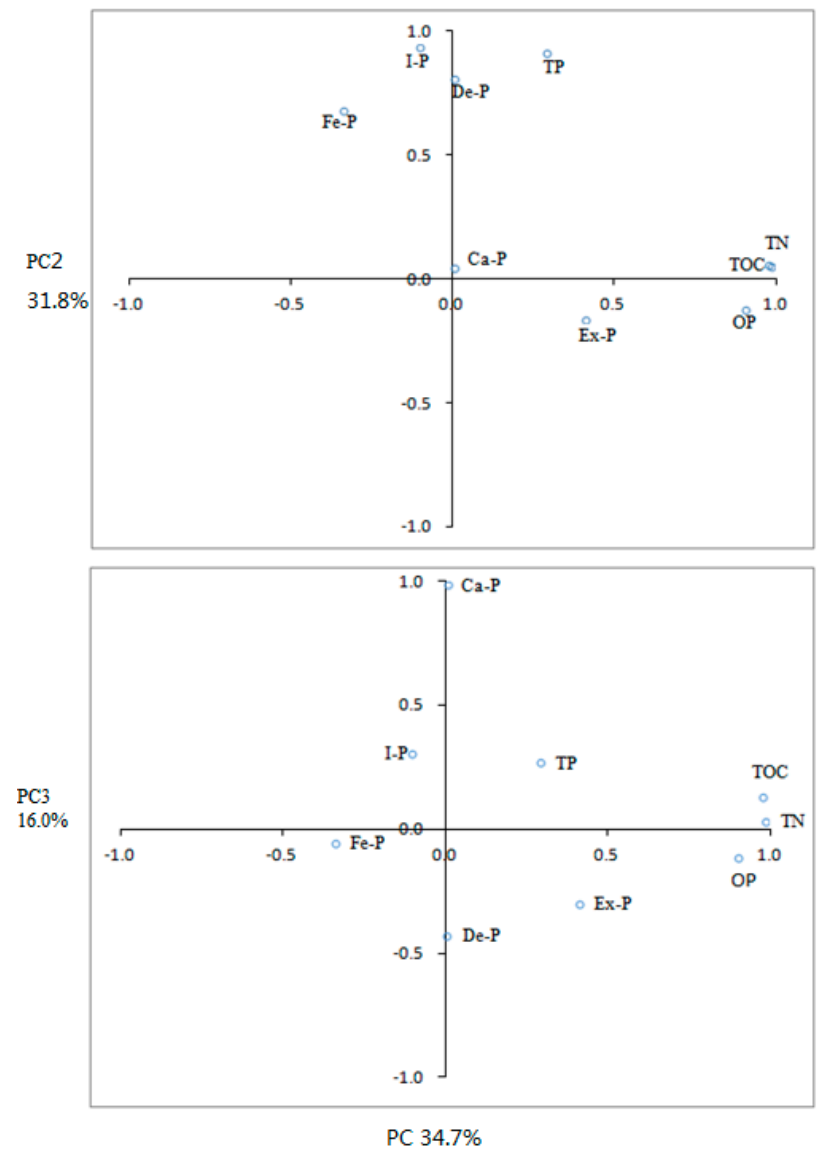

Figure 5. PCA loadings (PC1 versus $\mathrm{PC} 2$ and PC3) for different $\mathrm{P}$ fractions, $\mathrm{TN}$ and TOC in surface sediments.

\subsection{Sedimentary TOC to O-P}

The TOC/O-P ratio ranged from 199 to 609, with an average of 413 (Figure 6). The lowest value occurred at the site near the nuclear power stations.

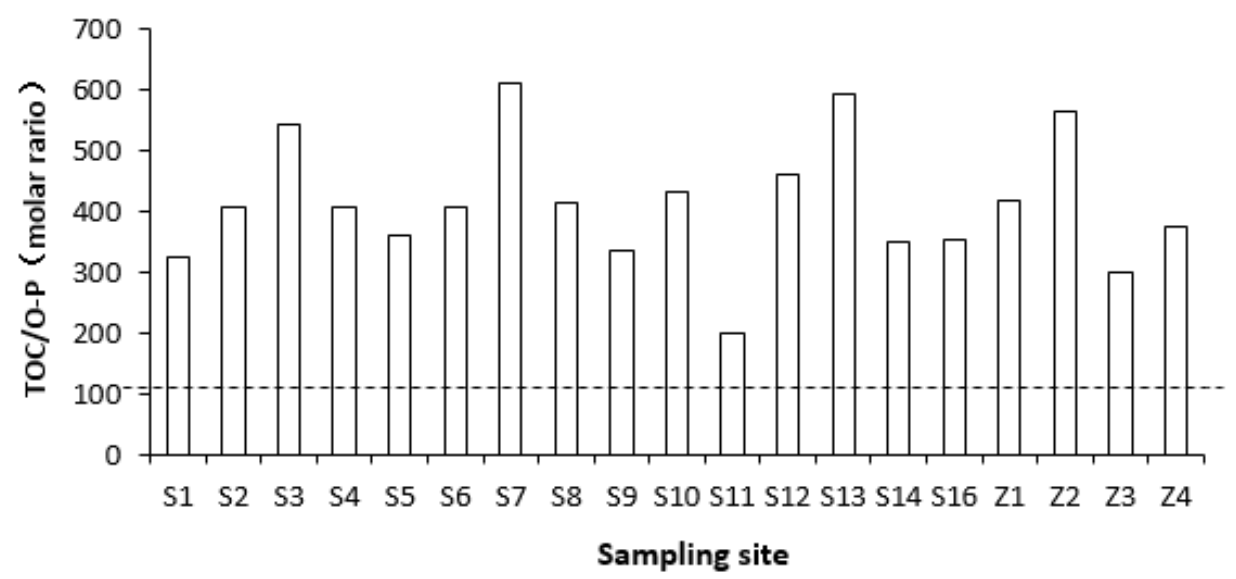

Figure 6. Atomic ratios of TOC and O-P in surface sediments of Daya Bay. 


\section{Discussion}

\subsection{Phosphorus species}

Ex-P is formed as phosphate adsorbs directly onto the surface of sediments minerals [22], and therefore it can be readily released and become available to phytoplankton [18]. In the present research, Ex-P contribute the lowest to TP (4\%), as was also found in Jiaozhou Bay [23], the East China Sea Shelf [24], Maowei Sea in the Beibu gulf [25], and Changjiang Estuary [26]. The average concentration $(15 \mu \mathrm{g} / \mathrm{g})$ was also in a similar range to these estuaries and bays (Table 4$)$, but it was much lower than that in South China Sea [27], south Long Island (USA) [28], Kalpakkam( India) [29], southern Caspian Sea [21], and the eastern coast of Hainan Island [30] (Table 4). Relatively high values of Ex-P were generally related to a high input of phosphate from the rivers or coastal sewage, such as in the Pearl River, Changjiang River, and Wanquan Rive [27,30-32]. The research indicates that organic matter may also be an important factor regulating the Ex-P concentration because of the high correlation of Ex-P with TOC contents [2,23]. However, Ex-P in Daya Bay was not significantly correlated with TOC or other parameters (Table 3). Exceptionally high values occurred at the mouth of Aotou Bay, but may be related to a combination of urban sewage and cage aquaculture. [14].

Table 4. The average concentration of different $P$ forms in surface sediments determined in this study compared with measurements from other estuaries and coastal seas $(\mu \mathrm{g} / \mathrm{g})$

\begin{tabular}{|c|c|c|c|c|c|c|c|c|}
\hline Locations & Ex-P & Fe-P & Ca-P & De-P & O-P & I-P & TP & References \\
\hline Daya Bay & 15.7 & 33.2 & 57.9 & 187.8 & 100.7 & 294.5 & 395.3 & $\begin{array}{l}\text { The present } \\
\text { study }\end{array}$ \\
\hline Central Pacific Ocean & 10.9 & 44.8 & 621.8 & 809.9 & 94.1 & & 1581.4 & [1] \\
\hline South China Sea & 43.2 & 34.9 & 127.8 & 154.1 & 115.2 & 345.8 & 461.0 & [2] \\
\hline Laizhou Bay & 10.7 & 40.7 & 60.2 & 320.0 & 62.1 & 423.6 & 493.7 & [18] \\
\hline Zhangzi Island & 13.1 & 36.6 & 31.4 & 145.4 & 49.4 & 226.0 & 275.6 & [18] \\
\hline $\begin{array}{l}\text { Long Island Sound, } \\
\text { USA }\end{array}$ & 34.9 & - & 126.4 & 178.8 & 95.9 & - & 436.0 & [20] \\
\hline Southern Caspian Sea & 46.4 & 73.5 & 158.2 & 177.9 & 79.6 & & 535.8 & [21] \\
\hline Bay of Seine & 25.3 & 42.5 & 186.4 & - & 75.5 & - & 329.0 & [22] \\
\hline $\begin{array}{l}\text { East China Sea shelf } \\
\text { (spring) }\end{array}$ & 13.8 & 21.9 & 148.0 & 153.0 & 91.7 & - & 428.4 & [24] \\
\hline $\begin{array}{l}\text { East China Sea shelf } \\
\text { (autumn) }\end{array}$ & 11.4 & 20.0 & 170.4 & 225.0 & 77.1 & - & 503.9 & [24] \\
\hline $\begin{array}{l}\text { Maowei Sea, } \\
\text { China(summer) }\end{array}$ & 15.3 & 125.2 & 57.9 & 52.6 & 156.6 & & 407.6 & [25] \\
\hline $\begin{array}{l}\text { Maowei Sea, } \\
\text { China(winter) }\end{array}$ & 16.6 & 77.1 & 33.0 & 57.3 & 113.0 & & 297.0 & [25] \\
\hline $\begin{array}{l}\text { Changjiang Estuary and } \\
\text { adjacent East China Sea } \\
\text { inner shelf }\end{array}$ & 14.0 & 13.7 & 29.4 & 302.4 & 183.4 & & 542.9 & [26] \\
\hline Kalpakkam, India & 63.6 & 58.3 & 737 & & 138.0 & & 997.0 & [29] \\
\hline Hailan island & 29.9 & 36.1 & 131.9 & 159.1 & 119.0 & 356.9 & 475.9 & [30] \\
\hline Little Madeira Bay & 2.3 & $<1$ & 73.7 & - & 65.2 & - & 106.0 & [32] \\
\hline Pearl River Delta & - & 79.7 & 30.5 & 222.6 & 167.0 & 334.0 & 501.0 & [33] \\
\hline Daya Bay & 19.7 & 27.4 & 92.9 & 127.7 & 51.1 & 290.8 & 341.9 & [34] \\
\hline
\end{tabular}

Notice: - no data available; some of the data were originally in $\mu \mathrm{mol} / \mathrm{g}$.

Fe-P can release phosphate with the decrease in environmental redox or under anoxic conditions [7,8]. In the present research, Fe-P contributed the second lowest to TP, as was also found in sediments of Hainan coastal area [30], East China Sea Shelf [24], Yellow Sea [35] and East China Sea [32] and the southern Caspian Sea [21]. The average concentration of Fe-P in Daya Bay $(33.2 \mu \mathrm{g} / \mathrm{g})$ was comparable to that in Zhangzi Island [18], South China Sea [2] and Hainan Island [30], higher than East China sea shelf, Little Maderia Bay, Changjiang estuary [24,26,35], and lower than that in Pearl River Delta [33], Laizhou Bay [18], Kalpakkam of India [29], Maowei Sea in Beibu Gulf [25], southern Caspian Sea [21] and the central Pacific Ocean [1] (Table 4). Many studies suggested that Fe-P decreases from brackish to saline water (relative high salinity) [31]. Conversely, the salinity of Daya Bay 
increased slowly from the inner to outer bay [13], but the highest Fe-P value occurred at the outer bay site, which should have relatively higher salinity and be less polluted. A more oxidized environment at the outer bay might shift soluble Fe (II) to particulate Fe (III) and enhance the adsorption of phosphate onto Fe oxides/hydroxides, thus increasing the content of Fe-P. This was supported by a negative correlation between Fe-P and O-P, though the significance was not reached $(\mathrm{r}=-0.394, p=0.095)$, indicating the need for further investigation.

Ca-P mainly indicates phosphorus incorporated with $\mathrm{CaCO}_{3}$, including biogenic apatite (bones, teeth, shell fragments, and calcareous phytoplankton, etc.), and authigenic carbonate fluorapatite (CFA) [30,31]. Averaged Ca-P concentration in Daya Bay was $57.92 \mu \mathrm{g} / \mathrm{g}$, which was relatively lower than in many other coastal and marine areas (Table 4), but higher than Zhangzi Island, Maowei sea and, Changjiang Estuary $[18,25,26]$. The content of Ca-P was highest in the nearby Danao River estuary and decreased gradually into the bay, which suggested a riverine input of Ca-P PCA analysis and indicated that PC3 had high loading for Ca-P only, suggesting a different source of Ca-P with other P fractions.

De-P includes detrital apatite and other P-containing minerals, and was the most abundant P fraction in Daya Bay, accounting for $47.5 \%$ of TP, which was similar to studies in other coastal areas [24,33]. Previous research suggested that the eroded soils enriched in De-P from upper basins of rivers resulted in a high contribution of De-P, such as that in the Yangtze River Estuary and adjacent East China Sea inner shelf [26,31], the Bohai and Yellow Seas, and the Yellow River Estuary [35], and the Pearl River Delta [33]. In other estuaries, such as the Amazon Estuary, because of river flow through tropical rainforests, grass, and fertile soils, the contribution of De-P was only 6\% of TP [1]. There are no major river flows, except the small Danao River in the northwest; the river had a high content of Ca-P and very low contribution of De-P (3.3\%), indicating that riverine input of De-P was negligible. The highest content of De-P occurred at sites S6 and S12, indicating sources from cage aquaculture.

O-P contributed an average of $25 \%$ of TP, which was comparable to that in South China Sea $(24.9 \%)$ [2], Hailan Island (25\%) [30], and Bay of Seine (22\%) [22], higher than that in Laizhou Bay, Zhanzi Island [18], East China Sea shelf [24], Kalpakkam [29] and southern Caspian Sea [21], but less than that in Pearl River Delta [35], Maowei Sea [25] and Changjiang Estuary [26]. The highest O-P concentration occurred at the northeast, around Fanhe bay, which was consistent with the surface sediment content of TOC and TN. Accordingly, O-P showed significant correlations with TOC ( $\mathrm{r}=0.856, p<0.0001)$ and $\mathrm{TN}(\mathrm{r}=0.844, p<0.0001)$. PCA analysis showed PC1 had high positive loadings on variables TN, TOC and O-P, suggesting similar sources of TN, TOC and OP. Significant positive correlations between TOC and O-P have been widely found in many other studies due to simultaneously bound TOC and O-P onto fine-grained sediments [2,18,23,29]. In addition, the higher O-P levels at Fanhe Bay were probably related to the discharge of intensive pond aquaculture effluents around the bay coast, which was also indicated by relatively higher chla at Fanhe Bay [13]. High phytoplankton biomass might also be deposited on the surface of sediment and result in a high content of TOC and O-P.

The average TP concentration of $395.3 \mu \mathrm{g} / \mathrm{g}(291 \sim 511 \mu \mathrm{g} / \mathrm{g})$ in the surface sediment of Daya Bay was similar to other Chinese estuaries and bays (Table 4). In Daya Bay, there was a small TP increase compared with a previous average of $341.9 \mu \mathrm{g} / \mathrm{kg}$ [34] due to an increase in O-P, while total I-P remained relatively stable, although the composition of I-P differed. According to sediment quality guidelines (SQGs, Ministry of Environment and Energy, Ontario, Canada) [36], sediment TN and TP content below 550 and $600 \mathrm{ug} / \mathrm{g}$, respectively, indicates low pollution. Therefore, Daya Bay had low phosphorus pollution, and moderate nitrogen pollution $(4800 \mathrm{mg} / \mathrm{kg}$, the severe pollution standard).

\subsection{Sedimentary Organic Carbon to Phosphorus Ratio}

The molar ratio of organic carbon to phosphorus (TOC/O-P) is widely used to determine the origin of sources of O-P and TOC [26,28]. According to Redfield ratio [3], the TOC/O-P of marine phytoplankton is generally close to 106 [37], so the organic matter in sediment originating from marine plankton sedimentation should be also around 106, while the ratio > 106 indicates land sources [21]. A lower value of the ratio may happen in the aerobic/suboxide areas with low TOC and/or dominance 
of bacterial biomass $[28,37]$. Due to different sources of terrestrial and marine organic matter, and/or preferential regeneration of organic carbon and phosphorus, TOC/TOP ratios in marine sediments range widely from 50 to 4500 [38,39]. TOC/O-P in the surface sediment of Daya Bay had a much higher value than Redfield ratio, indicating mainly terrestrial sources of organic matter, especially at sites S7, Z2 and S3, which were located in the busy harbor, aquaculture area and Danao River estuary, respectively. Another very high value was found at the most seaward site, S13, due to a very low content of O-P, which was significantly negatively correlated with salinity. The lowest value occurred adjacent to nuclear power stations (site 11), which had relatively lower content of TOC, most probably due to the higher decomposition of TOC at higher water temperatures caused by discharges of cooling water from the two nuclear power stations [40].

\subsection{Bioavailable Forms of P Phosphorus}

Bioavailable phosphorus (BAP) in sediment indicates the total amount of soluble phosphate that could be released directly and/or after conversion into the overlying water. Ex-P, Fe-P and O-P can be readily released [41], and the sum of the three fractions was considered as potential BAP. BAP concentration of surface sediments in Daya Bay ranged from 108 to $188 \mu \mathrm{g} / \mathrm{g}$, with an average concentration of $149.6 \mu \mathrm{g} / \mathrm{g}$, which contributed $37.8 \%(24.6 \sim 56.0 \%)$ of TP. The relatively high proportion was in similar range with that of the continental shelf region of the northern South China Sea $(36.7 \%)$, eastern coast of Hainan Island (38.6\%) and intertidal surface sediments of the YRE (37.4\%) [2,30,31]. This suggests that surface sediments of Daya Bay may be an important bioavailable P resevoir. Recent benthic nutient flux investigation indicate sediment was a P source for phytoplankton in summer and autumn, and was a P sink in winter and spring in Daya Bay [42]. Due to a rapid increase in dissolved inorganic nitrogen and marked decreased phosphate during recent decades, Daya Bay was believed to shift from nitrogen to phosphorus limitation since the 1980s to the mid-1990s. However, the average chla content kept an increasing trend [4]. The release of $P$ may play a role in supporting increased harmful algal blooms (HABs), which usually occur in the summer and autumn in Daya Bay [11,42]. Other research indicated that algal blooms may enhance the P release from sediment caused by pytoplankton exploitation of phosphate in the water column or mediated by physicochemical factors change coinciding with algal blooms [43]. However, further research on the interactions of phytoplankton with benthic P cycling in Daya Bay is needed.

To summarize, based on spatial distribution, PC and PCA analysis, sediment P in Daya bay is mainly derived from terrestrial sources, such as pond and cage aquaculture, riverine input and urban sewage. A high content of BAP in sediments indicates a high potential of phosphate supply to pelagic phytoplankton, especially the HABs. Cutting off the terrestrial sources of P in Daya Bay is essential for decreasing sediment phosphorus and the health of the ecosystem in the long term.

\section{Conclusions}

The concentration and spatial distribution of different fractions of $\mathrm{P}$ in surface sediment of Daya Bay were quantified through extraction methods. Like many coastal and marine areas, De-P was the dominant forms of $\mathrm{P}$, contributing $47.5 \%$ of TP, followed by O-P, contributing $25.5 \%$, while Ex-P and Fe-P contribute the lowest to TP. The concentration of sedimentary TP ranged from $290.3 \sim 525.1 \mu \mathrm{g} / \mathrm{g}$ with the average of $395.3 \mu \mathrm{g} / \mathrm{g}$, which was in similar range to other estuaries and coasts. Different fractions of phosphorus showed different spatial distributions due to different sources, which were mainly derived from terrestrial sources, such as pond and cage aquaculture, riverine input and urban sewage. The molar ratio of organic carbon to phosphorus (TOC/O-P) ranged from 199 to 609, and was much higher than the Redfield ratio, suggesting terrestrial sources of organic matter in Daya Bay surface sediments. The average bioavailable phosphorus was $149.6 \mu \mathrm{g} / \mathrm{g}$ and contributed $37.8 \%$ (24.6 56.0\%) of TP, indicating that the surface sediments of Day Bay act as an important internal source of $P$. 
Author Contributions: F Data curation, L.G.; Formal analysis, C.P.; Methodology, H.L.; Software and investigation, Z.K.; Supervision, H.T.; Writing-original draft and review H.L. and H.T. All authors have read and agreed to the published version of the manuscript.

Funding: This research was funded by Key R\&D Program of Guangdong Province, grant number No.2019B020219003 and National Nature Science Foundation of China, grant number No. 31670458.

Acknowledgments: This work was supported in part by Key R\&D Program of Guangdong Province with No.2019B020219003 and the National Nature Science Foundation of China (31670458).

Conflicts of Interest: The authors declare no conflict of interest.

\section{References}

1. Ni, J.Y.; Lin, P.; Zhen, Y.; Yao, X.Y.; Guo, L.D. Distribution, source and chemical speciation of phosphorus in surface sediments of the central Pacific Ocean. Deep-Sea Res. 2015, 105, 74-82. [CrossRef]

2. Yang, B.; Liu, S.M.; Zhang, G.L. Geochemical characteristics of phosphorus in surface sediments from the continental shelf region of the northern South China Sea. Mar. Chem. 2018, 198, 44-55. [CrossRef]

3. Redfield, A.C.; Ketchum, B.H.; Richards, F.A. The influence of organisms on the composition of sea water. In The Sea, Ideas and Observations on Progress in the Study of the Seas; Hill, M.N., Ed.; Interscience: New York, NY, USA, 1963; pp. 29-77.

4. Wu, M.L.; Wang, Y.S.; Wang, Y.T.; Yin, J.P.; Dong, J.D.; Jiang, Z.Y.; Sun, F.L. Scenarios of nutrient alterations and responses of phytoplankton in changing Daya Bay, South China Sea. J. Mar. Syst. 2017, 165, 1-12. [CrossRef]

5. Cao, X.Y.; Zhu, J.M.; Lu, M.; Ge, C.F.; Zhou, L.M.; Yang, G.M. Phosphorus sorption behavior on sediments in Sanggou Bay related with their compositions by sequential fractionation. Ecotox. Environ. Saf. 2019, 169, 144-149. [CrossRef]

6. Junior, L.C.C.; Da Costa Machado, E.; Brandini, N.; Zem, R.C.; Knoppers, B.A. Distributions of total, inorganic and organic phosphorus in surface and recent sediments of the sub-tropical and semi-pristine Guaratuba Bay estuary, SE Brazil. Environ. Earth Sci. 2014, 72, 373-386. [CrossRef]

7. Yan, Y.; Gao, B.; Hao, H.; Zhou, H.D.; Lu, J. Nitrogen and phosphorus in sediments in China: A national-scale assessment and review. Sci. Total Environ. 2017, 576, 840-849.

8. Barik, S.K.; Bramh, S.; Bastia, T.K.; Behera, D.; Mohanty, P.K.; Rath, P. Distribution of geochemical fractions of phosphorus and its ecological risk in sediment cores of a largest brackish water lake, South Asia. Int. J. Sediment Res. 2019, 34, 251-261. [CrossRef]

9. Tang, H.J.; Ke, Z.X.; Yan, M.T.; Wang, W.J.; Nie, H.Y.; Li, B.X.; Zhang, J.P.; Xu, X.R.; Wang, J. Concentrations, Distribution, and Ecological Risk Assessment of Heavy Metals in Daya Bay, China. Water 2018, 10, 780. [CrossRef]

10. Wang, Y.S. Ecological environment changes in Daya Bay, China, from 1982-2004. Mar. Pollut. Bull. 2008, 56, 1871-1879. [CrossRef]

11. Ni, Z.; Zhang, L.; Yu, S.; Jiang, Z.; Zhang, J.; Wu, Y.; Zhao, C.; Liu, S.; Zhou, C.; Huang, X. The porewater nutrient and heavy metal characteristics in sediment cores and their benthic fluxes in Daya Bay, South China. Mar. Pollut. Bull. 2017, 124, 547-554. [CrossRef]

12. Li, L.; LÜ, S.H.; Cen, J.Y. Spatio-temporal variations of harmful algal blooms along the coast of Guangdong, Southern China during 1980-2016. J. Oceanol. Limnol. 2019, 37, 535-551. [CrossRef]

13. Ke, Z.X.; Tan, Y.H.; Huang, L.M.; Liu, J.X.; Xiang, C.H.; Zhao, C.Y.; Zhang, J.P. Significantly depleted ${ }^{15} \mathrm{~N}$ in suspended particulate organic matter indicating a strong influence of sewage loading in Daya Bay, China. Sci. Total Environ. 2019, 650, 759-768. [CrossRef] [PubMed]

14. Zhang, L.; Ni, Z.X.; Wu, Y.C.; Zhao, C.Y.; Liu, S.L.; Huang, X.P. Concentrations of porewater heavy metals, their benthic fluxes and the potential ecological risks in Daya Bay, South China. Mar. Pollut. Bull. 2020, 150, 110808. [CrossRef]

15. Qu, B.X.; Song, J.M.; Yuan, H.M.; Li, X.G.; Li, N.; Duan, L.Q. Intensive anthropogenic activities had affected Daya Bay in South China Sea since the 1980s: Evidence from heavy metal contaminations. Mar. Pollut. Bull. 2018, 135, 318-331. [CrossRef] [PubMed] 
16. Fang, S.M.; Zhang, X.M.; Bao, L.J.; Zeng, E.Y. Modeling the fate of $\mathrm{P}, \mathrm{P}^{\prime}$-DDT in water and sediment of two typical estuarine bays in South China: Importance of fishing vessels' inputs. Environ. Pollut. 2016, 212, 598-604. [CrossRef] [PubMed]

17. Sun, R.X.; Lin, Q.; Ke, C.L.; Du, F.Y.; Gu, Y.G.; Cao, K.; Luo, X.J.; Mai, B.X. Polycyclic aromatic hydrocarbons in surface sediments and marine organisms from the Daya Bay, South China. Mar. Pollut. Bull. 2016, 103, 325-332. [CrossRef] [PubMed]

18. Zhuang, W.; Gao, X.L.; Zhang, Y.; Xing, Q.G.; Tosi, L.; Qin, S. Geochemical characteristics of phosphorus in surface sediments of two major Chinese mariculture areas: The Laizhou Bay and the coastal waters of the Zhangzi Island. Mar. Pollut. Bull. 2014, 83, 343-351. [CrossRef]

19. Li, G.; Hu, B.; Bi, J.; Leng, Q.; Xiao, C.; Yang, Z. Heavy metals distribution and contamination in surface sediments of the coastal Shandong Peninsula (Yellow Sea). Mar. Pollut. Bull. 2013, 76, 420-426. [CrossRef]

20. Ruttenberg, K.C. Development of a sequential extraction method for different forms of phosphorus in marine sediments. Limnol. Oceanogr. 1992, 37, 1460-1482. [CrossRef]

21. Bastami, K.D.; Neyestani, M.R.; Raeisi, H.; Shafeian, E.; Baniamam, M.; Shirzadi, A.; Esmaeilzadeh, M.; Mozaffari, S.; Shahrokhi, B. Bioavailability and geochemical speciation of phosphorus in surface sediments of the Southern Caspian Sea. Mar. Pollut. Bull. 2018, 126, 51-57. [CrossRef]

22. Andrieux, F.; Aminot, A. A two-year survey of phosphorus speciation in the sediments of the Bay of Seine (France). Cont. Shelf Res. 1997, 17, 1229-1245. [CrossRef]

23. Kang, X.M.; Song, J.M.; Yuan, H.M.; Shi, X.; Yang, W.F.; Li, X.G.; Li, N.; Duan, L.Q. Phosphorus speciation and its bioavailability in sediments of the Jiaozhou Bay. Estuar. Coast. Shelf Sci. 2017, 188, 127-136. [CrossRef]

24. Zhou, F.X.; Gao, X.L.; Yuan, H.M.; Song, J.M.; Chen, C.T.A.; Liu, H.K.; Zhang, Y. Geochemical forms and seasonal variations of phosphorus in surface sediments of the East China Sea shelf. J. Mar. Syst. 2016, 159, 41-54. [CrossRef]

25. Yang, B.; Zhou, J.B.; Lu, D.L.; Dan, S.F.; Zhang, D.; Lan, W.L.; Kang, Z.J.; Ning, Z.M.; Cui, D.Y. Phosphorus chemical speciation and seasonal variations in surface sediments of the Maowei Sea, northern Beibu Gulf. Mar. Pollut. Bull. 2019, 141, 61-69. [CrossRef] [PubMed]

26. Meng, J.; Yao, P.; Yu, Z.; Bianchi, T.; Zhao, B.; Pan, H.H.; Li, D. Speciation, bioavailability and preservation of phosphorus in surface sediments of the Changiang Estuary and adjacent East China Sea inner shelf. Estuar. Coast. Shelf Sci. 2014, 144, 27-38. [CrossRef]

27. Yang, B.; Kang, Z.J.; Lu, D.L.; Dan, S.F.; Ning, Z.M.; Lanand, W.L.; Zhong, Q.P. Spatial Variations in the Abundance and Chemical Speciation of Phosphorus across the River-Sea Interface in the Northern Beibu Gulf. Water 2018, 10, 1103. [CrossRef]

28. Ruttenberg, K.C.; Goni, M.A. Phosphorus distribution, C: N: P ratios, and $\delta^{13} \mathrm{C}_{\mathrm{oc}}$ in arctic, temperature, and tropical coastal sediments: Tools for characterizing bulk sedimentary organic matter. Mar. Geol. 1997, 139, 123-145. [CrossRef]

29. Bramha, S.N.; Mohanty, A.K.; Padhi, R.K.; Panigrahi, S.N.; Satpathy, K.K. Phosphorus speciation in the marine sediment of Kalpakkam coast, southeast coast of India. Environ. Monit. Assess. 2014, 186, 6003-6015. [CrossRef]

30. Yang, B.; Liu, S.M.; Wu, Y.; Zhang, J. Phosphorus speciation and availability in sediments off the eastern coast of Hainan Island, South China Sea. Cont. Shelf Res. 2016, 118, 111-127. [CrossRef]

31. Hou, L.J.; Liu, M.; Yang, Y.; Ou, D.N.; Lin, X.; Chen, H.; Xu, S.Y. Phosphorus speciation and availability in intertidal sediments of the Yangtze Estuary, China. Appl. Geochem. 2009, 24, 120-128. [CrossRef]

32. Koch, M.S.; Benzr, E.; Rudnick, D.T. Solid-phase phosphorus pools in highly organic carb on ate sediment s of Northeastern Florida Bay. Estuar. Coast. Shelf Sci. 2001, 52, 279-291. [CrossRef]

33. Hu, C.Y.; Pan, J.M.; Liu, X.Y. Species of phosphorus in sediments from Pearl River Estuary. Mar. Environ. Sci. 2001, 20, 21-25. (In Chinese)

34. He, T.; Xie, J.; Yu, H.S.; Fang, H.D. Distribution characteristics of phosphorus forms in surface sediments in the Daya Bay. Acta Sci. Nat. Univ. Sunyatseni 2010, 49, 126-131. (In Chinese)

35. Liu, S.M.; Zhang, J.; Li, D.J. Phosphorus cycling in sediments of the Bohai and Yellow Seas. Estuar. Coast. Shelf Sci. 2004, 59, 209-218. [CrossRef]

36. Persaud, D.; Jaagumagi, R.; Hayton, A. Guidelines for the Protection and Management of Aquatic Sediment Quality in Ontario; Water Resources Branch, Ontario Ministry of the Environment: Toronto, ON, Canada, 1993. 
37. Ingall, E.D.; Cappellen, P.V. Relation between sedimentation rate and burial of organic phosphorus and organic carbon in marine sediments. Geochim. Cosmochim. Acta 1990, 54, 373-386. [CrossRef]

38. Anderson, L.A.; Sarmiento, J.L. Redfield ratios of remineralization determined by nutrient data analysis. Glob. Biogeochem. Cycles 1994, 8, 65-80. [CrossRef]

39. Sekula-Wood, E.; Benitez-Nelson, C.R.; Bennett, M.A.; Thunell, R. Magnitude and composition of sinking particulate phosphorus fluxes in Santa Barbara Basin, California. Glob. Biogeochem. Cycles 2012, 26, 1-15. [CrossRef]

40. Song, X.Y.; Huang, L.M.; Zhang, J.L.; Huang, X.P.; Zhang, J.B.; Yin, J.Q.; Tan, Y.H.; Liu, S. Variation of phytoplankton biomass and primary production in Daya Bay during spring and summer. Mar. Pollut. Bull. 2004, 49, 1036-1044. [CrossRef]

41. Cui, H.; Ou, Y.; Wang, L.X.; Yan, B.X.; Han, L.; Li, Y.X. Change in the Distribution of Phosphorus Fractions in Aggregates under Different Land Uses: A Case in Sanjiang Plain, Northeast China. Int. Environ. Res. Public Health 2019, 16, 212. [CrossRef]

42. Zhang, L.; Xiong, L.; Zhang, J.; Jiang, Z.; Zhao, C.; Wu, Y.; Liu, S.; Huang, X. The benthic fluxes of nutrients and the potential influences of sediment on the eutrophication in Daya Bay, South China. Mar. Pollut. Bull. 2019, 149, 110540. [CrossRef]

43. Xie, L.Q.; Xie, P.; Tang, H.J. Enhancement of dissolved phosphorus release from sediment to lake water by Microcystis blooms-An enclosure experiment in a hyper-eutrophic, subtropical Chinese lake. Environ. Pollut. 2003, 122, 391-399. [CrossRef]

(C) 2020 by the authors. Licensee MDPI, Basel, Switzerland. This article is an open access article distributed under the terms and conditions of the Creative Commons Attribution (CC BY) license (http://creativecommons.org/licenses/by/4.0/). 